\title{
Analisis Reduksi Intensitas Cahaya Pada Smartphones' Screen Protector Dan Dampaknya Pada Mata
}

\author{
Bhekti Kumorowati ${ }^{1)}$, Masturi ${ }^{2)}$, Ian Yulianti ${ }^{3)}$, Fuad Ardani Rahman ${ }^{4)}$ \\ ${ }^{1,2,3)}$ Prodi Pendidikan Fisika Universitas Negeri Semarang, Bendan Ngisor, Semarang, 50233 \\ ${ }^{4)}$ Prodi Teknika PIP Semarang, Jalan Singosari No.2A, Semarang, Indonesia 50241
}

${ }^{1)}$ Email: bhektikumorowati@students.unnes.ac.id

\begin{abstract}
Abstrak. Analisis reduksi intensitas cahaya yang melewati screen protector dan identifikasi kemampuan screen protector sebagai pelindung mata dilakukan dengan mengukur reduksi intensitas cahaya menggunakan luxmeter, kemudian menetapkan fokus bahasan yang mencakup kemampuan cahaya menembus screen protector dan analisis fisis screen protector sebagai pelindung mata. Peran sebagai pelindung mata dikaji melalui pendekatan peristiwa polarisasi yaitu proses terserapnya sebagian arah getar cahaya. Dihasilkan sebagian arah getar cahaya layar smartphone sebelum masuk ke mata akan terserap oleh screen protector sehingga dapat memperlambat terjadinya degenerasi makula. Rekomendasi pemilihan screen protector bergantung pada besarnya koefisien atenuasi (koefisien penyerapan) yang dimiliki masing-masing screen protector. Koefisien atenuasi terbesar dimiliki oleh screen protector jenis anti spy.
\end{abstract}

Kata Kunci: Screen Protector, Intensitas Cahaya, Efek Fotolistrik, Degenerasi Makula

\section{PENDAHULUAN}

Smartphone sudah menjadi gaya hidup masyarakat Indonesia yang tidak dapat dihindari. Survey yang dilakukan Yahoo pada tahun 2012 menunjukkan pengguna smartphone terbanyak di Indonesia yaitu pada usia 15 - 19 tahun (kalangan SMA) dengan persentase $47,9 \%$ dari seluruh kalangan jenjang pendidikan [1]. Selanjutnya berdasarkan informasi dari lembaga riset digital Emarketer memperkirakan pada tahun 2019 pengguna smartphone di Indonesia akan meningkat $66 \%$ dari tahun 2015. Peningkatan tersebut menjadikan Indonesia sebagai pengguna smartphone terbanyak ketiga di kawasan Asia Pasifik [2].

Hasil survei oleh Brown pada tahun 2014 menjelaskan bahwa penggunaan rata-rata smartphone di Indonesia adalah 181 menit per hari. Hal ini menjadikan Indonesia berada pada posisi pertama untuk penggunaan smartphone terlama di dunia [3] sekaligus posisi pertama untuk penderita kerusakan mata akibat radiasi layar smartphone. Layar smartphone akan memancarkan sinar biru yang dapat merusak jaringan penglihatan. Untuk melindungi mata dari radiasi ini, diciptakan kacamata yang dilengkapi dengan lapisan anti sinar biru. Kacamata ini bekerja dengan memanfaatkan sifat polarisasi cahaya.

Polarisasi cahaya merupakan peristiwa terserapnya arah getar cahaya pada gelombang transversal seperti cahaya matahari. Terserapnya arah getar ditandai dengan berkurangnya intensitas cahaya yang melewati suatu medium [4], termasuk plastik dan kaca.

Sementara itu, terdapat accesories smartphone yang terbuat dari kaca atau plastik untuk melindungi layar smartphone dari goresan benda tajam, yaitu screen protector. Berdasarkan pernyataan di atas bahwa polarisasi dapat terjadi pada medium kaca dan plastik, maka polarisasi dapat terjadi pada screen protector sehingga diasumsikan dapat melindungi mata dari kerusakan akibat sinar biru yang dipancarkan layar smartphone. Oleh karena itu, penelitian ini bertujuan untuk menganalisis reduksi cahaya yang dipancarkan layar smartphone dan menyelidiki potensi screen protector dalam memberikan perlindungan untuk mata. 


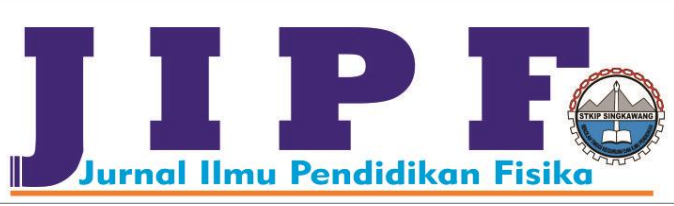

\section{METODE}

Diawali dengan mengukur intensitas cahaya layar smartphone sebelum dan setelah menembus screen protector menggunakan luxmeter kemudian hasil pengukuran dianalisis. Jenis screen protector dan fungsi pendukungnya ditampilkan pada Tabel 1 sedangkan layar smartphone yang digunakan adalah jenis TFT capasitive touchscreen dengan 16 milyar warna. Layar TFT (Thin Film Transistor) merupakan jenis layar yang sering digunakan pada smartphone kelas menengah ke bawah. Jenis layar ini menggunakan teknologi LCD (Liquid Crystal Display) sehingga meningkatkan kualitas warna dan resolusi layar smartphone. Meskipun demikian, konsumsi daya smartphone yang menggunakan layar ini cukup besar.

TABEL 1.

JENIS SCREEN PROTECTOR DAN KARAKTERISTIKNYA

\begin{tabular}{|c|c|c|c|}
\hline No. & Jenis & Material & Karakteristik \\
\hline 1 & $\begin{array}{l}\text { Transparent } \\
\text { Glass }\end{array}$ & Plastik & $\begin{array}{l}\text { Melindungi layar dari goresan } \\
\text { ringan dan paling jernih diantara } \\
\text { jenis lainnya (layar tidak terlihat } \\
\text { gelap) }\end{array}$ \\
\hline 2 & Anti Glare & Plastik & $\begin{array}{l}\text { Seperti Transparent Glass, } \\
\text { mengurangi/ meminimalisir } \\
\text { sentuhan minyak dari jari atau } \\
\text { benda lainnya (anti minyak), anti } \\
\text { silau ketika menggunakan } \\
\text { smartphone yang langsung } \\
\text { terpapar sinar matahari }\end{array}$ \\
\hline 3 & Anti Spy & Plastik & $\begin{array}{l}\text { Menjaga privasi pengguna } \\
\text { karena isi smartphone hanya } \\
\text { terlihat dari arah tegak lurus } \\
\text { bidang layar, layar terlihat lebih } \\
\text { gelap, lebih tebal sehingga } \\
\text { mengurangi kesensitifan pada } \\
\text { smartphone jenis layar sentuh }\end{array}$ \\
\hline 4 & $\begin{array}{l}\text { Mirror } \\
\text { Glass }\end{array}$ & Plastik & $\begin{array}{l}\text { Berperan seperti cermin ketika } \\
\text { layar smartphone mati karena } \\
\text { dilengkapi dengan lapisan } \\
\text { konduktor, layar terlihat lebih } \\
\text { gelap }\end{array}$ \\
\hline 5 & $\begin{array}{l}\text { Tempered } \\
\text { Glass }\end{array}$ & Kaca & $\begin{array}{l}\text { Paling baik dalam melindungi } \\
\text { layar smartphone dari goresan, } \\
\text { layar terlihat jelas dan lebih } \\
\text { tajam. Merupakan jenis screen } \\
\text { protector dengan harga paling } \\
\text { mahal. }\end{array}$ \\
\hline
\end{tabular}

Percobaan ini dilakukan dalam kondisi gelap agar intensitas yang terukur luxmeter mendekati intensitas sebenarnya. Luxmeter digunakan untuk mengukur Iluminasi sumber cahaya dari sumber cahaya. Iluminasi merupakan besaran intensitas
Jurnal Ilmu Pendidikan Fisika

Volum 1 Nomor 1 Maret 2017. Page 1-4. p-ISSN: 2477-5959 e-ISSN: 2477-8451

penerangan dari cahaya yang mengenai suatu permukaan dengan satuan lux atau lumen/m2 dengan simbol $E_{p}$.

$$
E_{p}=\frac{I}{r^{2}}
$$

Keterangan:

$E_{p}=$ Intensitas Penerangan (Lux)

$I$ = Intensitas Cahaya (Lumen atau Candela/ Steradian)

$r=$ Jarak sumber cahaya dari titik pengamatan (m2)

Persamaan (1) menunjukkan bahwa intensitas penerangan sebanding dengan intensitas cahaya dan berbanding terbalik dengan kuadrat jarak sumber cahaya dari titik pengamatan. Pengukuran besarnya iluminasi berjarak sangat dekat (mendekati nol), maka kuadrat jarak ini bernilai sangat kecil. Oleh karena itu, dapat dilakukan pendekatan bahwa besarnya intensitas penerangan yang terukur oleh luxmeter diasumsikan sebagai intensitas cahaya.

Persentase reduksi dihitung untuk mengetahui terdapat pengurangan atau penambahan intensitas cahaya setelah menembus screen protector yang dihitung dengan persamaan (2). $I_{i}$ adalah intensitas cahaya sebelum melewati screen protector dan $I_{f}$ adalah intensitas cahaya setelah melewati screen protector.

$$
\text { Reduksi Intensitas Cahaya }=\frac{I_{f}-I_{i}}{I_{i}} \times 100 \%
$$

Ketika cahaya melewati screen protector, maka sebagian cahaya tersebut akan berkurang atau bertambah sesuai dengan persamaan LambertBeer pada persamaan (3) dengan $\alpha$ adalah koefisien atenuasi (koefisien penyerapan). Koefisien penyerapan ini menunjukkan karakteristik bahan menyerap intensitas cahaya yang mengenainya.

$$
I_{f}=I_{i} e^{-\alpha}
$$

\section{HASIL DAN PEMBAHASAN}

Hasil pengukuran disajikan pada Tabel 2 . Persentase reduksi intensitas cahaya dihitung dengan persamaan (2) akan menghasilkan nilai negatif. Tanda negatif menunjukkan terjadi penurunan intensitas cahaya setelah melewati lensa kontak. Misal data sampel A, hasil 


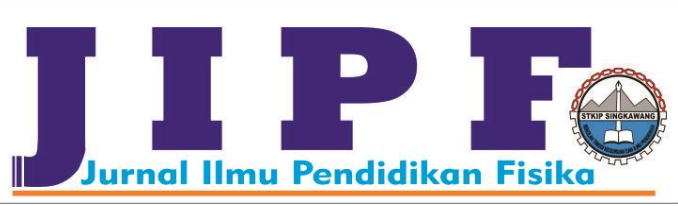

perhitungan dengan menggunakan persamaan (2) dihasilkan -7,59\%, artinya sampel A mampu mengurangi intensitas cahaya 7,59\%. Pada Tabel 2 , persentase reduksi ditampilkan nilai positif untuk memudahkan membaca data. Peristiwa tersebut bersesuaian dengan peristiwa polarisasi dimana intensitas cahaya yang melewati screen protector akan berkurang.

TABEL 2

HASIL PENGUKURAN INTENSITAS CAHAYA LAYAR SMARTPHONE

\begin{tabular}{|c|c|c|c|c|c|}
\hline \multirow[t]{2}{*}{$\begin{array}{l}\text { Sampe } \\
1\end{array}$} & \multirow[t]{2}{*}{$\begin{array}{c}\text { Jenis } \\
\text { Screen } \\
\text { Protektor }\end{array}$} & \multicolumn{2}{|c|}{$\begin{array}{c}\text { Cahaya } \\
\text { Layar } \\
\text { Smartphon } \\
\text { e (lux) }\end{array}$} & \multirow[t]{2}{*}{$\begin{array}{l}\text { Persentas } \\
\text { e Reduksi }\end{array}$} & \multirow[t]{2}{*}{$\begin{array}{c}\text { Koefisien } \\
\text { Penyerapa } \\
\text { n }\end{array}$} \\
\hline & & Ii & If & & \\
\hline A & $\begin{array}{c}\text { Transparen } \\
\text { t Glass }\end{array}$ & & 280 & 7,59 & 0,08 \\
\hline B & Anti Glare & & 286 & 5,61 & 0,06 \\
\hline $\mathrm{C}$ & Anti Spy & 303 & 69 & 77,23 & 1,48 \\
\hline D & $\begin{array}{c}\text { Mirror } \\
\text { Glass }\end{array}$ & 303 & 194 & 35,97 & 0,45 \\
\hline $\mathrm{E}$ & $\begin{array}{l}\text { Tempered } \\
\text { Glass }\end{array}$ & & 288 & 4,95 & 0,05 \\
\hline
\end{tabular}

Koefisien penyerapan secara berturut-turut dari yang terbesar ke yang terkecil dimiliki oleh sampel C, D, A, B, dan E. Sampel A, B, dan E cenderung bernilai sama, padahal sampel A dan B terbuat dari plastik sedangkan sampel $\mathrm{E}$ terbuat dari kaca. Hal ini menunjukkan bahwa besarnya koefisien penyerapan tidak bergantung oleh bahan pembuat screen protector. Sampel D memiliki lapisan konduktor berwarna gelap yang dapat memantulkan kembali cahaya baik dari layar atau lingkungan. Karena itu, intensitas cahaya ada yang dibiaskan dan dipantulkan sehingga koefisien penyerapan sampel D cukup besar yaitu 0,45. Sampel C memiliki koefisien terbesar yaitu 1,48 . Sampel C memiliki karakteristik yang unik dimana isi smartphone hanya bisa dilihat jelas dari arah tegak lurus bidang layar sehingga sampel C mampu menyerap arah getar cahaya lebih banyak dan hanya meloloskan arah getar yang tegak lurus dengan layar.

Telah disebutkan bahwa layar smartphone akan memancarkan sinar biru. Karakteristik sinar biru ditampilkan pada Tabel 3.
Jurnal Ilmu Pendidikan Fisika Volum 1 Nomor 1 Maret 2017. Page 1-4. p-ISSN: 2477-5959 e-ISSN: 2477-8451

TABEL 3

KARAKTERISTIK SINAR BIRU

\begin{tabular}{cc}
\hline Besaran & Besar \\
\hline Panjang Gelombang & $\left(4,50 \times 10^{-7}-4,95 \times 10^{-7}\right) \mathrm{m}$ \\
Frekuensi & $\left(6,06 \times 10^{14}-6,67 \times 10^{14}\right) \mathrm{Hz}$ \\
Energi & $\left(4,00 \times 10^{-19}-4,40 \times 10^{-19}\right) \mathrm{J}$ \\
\hline
\end{tabular}

Energi yang dihasilkan sinar biru sangat berpotensi menyebabkan degenerasi makula. Penderita degenerasi makula akan mengalami gangguan pada penglihatan sentralnya karena sel pada makulanya sudah rusak akibat paparan sinar biru [5]. Jika dikaitkan dengan fisika kuantum, degenerasi makula dapat dianalogikan dengan efek fotolistrik.

Efek fotolistrik adalah gejala terlepasnya elektron pada logam akibat disinari cahaya atau gelombang elektromagnetik pada umumnya [6]. Beberapa kesimpulan dari percobaan efek fotolistrik yaitu penyebab elektron terlepas dari logam adalah panjang gelombang cahaya yang menumbuk logam dengan nilai tertentu (harus lebih kecil dari panjang gelombang ambang), intensitas cahaya hanya akan meningkatkan jumlah fotoelektron, yaitu elektron yang terlepas dari logam [6]. Sumber cahaya dengan frekuensi sama dan intensitas berbeda, fotoelektron dihasilkan lebih banyak oleh sumber cahaya dengan intensitas yang lebih kuat [7]. Intensitas cahaya diartikan sebagai energi tiap foton dikalikan cacah foton yang menembus satu satuan luas permukaan secara tegak lurus tiap satu satuan waktu. Dengan demikian, besar kecilnya intensitas cahaya menunjukkan besar kecilnya cacah foton yang mengenai logam.

Frekuensi merupakan besaran yang berbanding terbalik dengan panjang gelombang $\left(f=\frac{c}{\lambda}\right) ; f$ adalah frekuensi cahaya $(\mathrm{Hz}), \mathrm{c}$ adalah kecepatan cahaya $(3 \times 108) \mathrm{m} / \mathrm{s}, \lambda$ adalah panjang gelombang (m), maka dapat dikatakan bahwa terlepasnya logam pada efek fotolistrik diakibatkan oleh cahaya dengan panjang gelombang tertentu. Jadi, jika logam ditumbuk dengan cahaya yang memiliki panjang gelombang lebih dari panjang gelombang ambang, maka elektron pada logam tidak akan terlepas dan sebesar apapun intensitas cahaya yang dihasilkan oleh cahaya tersebut tidak 


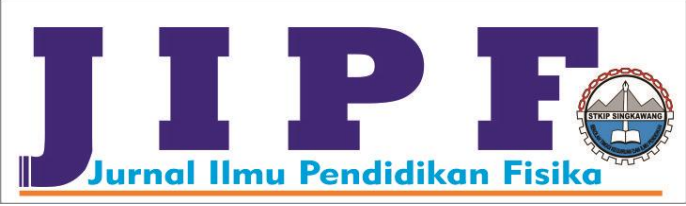

akan meningkatkan jumlah elektron karena tidak ada elektron yang dilepaskan.

Kesesuaian analogi dijelaskan dengan memisalkan makula mata sebagai logam dan sinar biru sebagai sumber cahaya yang mengenai mata atau logam. Berdasarkan kesimpulan percobaan efek fotolistrik, maka tidak semua jenis sinar dapat menyebabkan kerusakan makula, hanya sinar dengan panjang gelombang atau frekuensi atau energi tertentu yang dapat menyebabkan kerusakan makula. Dalam kasus ini, sinar biru merupakan sinar dengan energi yang cukup untuk merusak makula. Sedangkan peningkatan intensitas sinar biru hanya akan mempercepat terjadinya degenerasi makula. Makula adalah bagian dari retina yang berfungsi sebagai penglihatan tengah, penderita degenerasi makula akan mengalami gangguan pada penglihatan sentralnya karena sel pada makulanya sudah rusak akibat paparan sinar sinar biru. Oleh karena itu, penggunaan screen protector pada layar smartphone tidak mampu mencegah degenerasi makula, tetapi mampu memperlambat terjadinya degenerasi makula.

Berikut disajikan Tabel 4 untuk memberikan rekomendasi pemilihan screen protector. Peringkat yang sama menunjukkan tidak ada perbedaan performa yang signifikan.

TABEL 4

PEMERINGKATAN PERFORMA SCREEN PROTECTOR

\begin{tabular}{lcccc}
\hline $\begin{array}{c}\text { Jenis } \\
\text { Screen } \\
\text { Protector }\end{array}$ & $\begin{array}{c}\text { Ketajama } \\
\text { n Layar }\end{array}$ & $\begin{array}{c}\text { Sensitifita } \\
\text { s } \\
\text { Sentuhan }\end{array}$ & $\begin{array}{c}\text { Ketahana } \\
\text { n } \\
\text { terhadap } \\
\text { Goresan }\end{array}$ & $\begin{array}{c}\text { Daya } \\
\text { Reduksi } \\
\text { Intensita } \\
\text { S Cahaya }\end{array}$ \\
\hline $\begin{array}{l}\text { Transparen } \\
\text { t Glass }\end{array}$ & 2 & 1 & 3 & 3 \\
Anti Glare & 2 & 1 & 3 & 3 \\
Anti Spy & 4 & 2 & 2 & 1 \\
Mirror & 3 & 1 & 3 & 2 \\
Glass & & 1 & 1 & 3 \\
$\begin{array}{l}\text { Tempered } \\
\text { Glass }\end{array}$ & 1 & & & \\
\hline
\end{tabular}

Jurnal Ilmu Pendidikan Fisika

Volum 1 Nomor 1 Maret 2017. Page 1-4. p-ISSN: 2477-5959 e-ISSN: 2477-8451

\section{IV.KESIMPULAN}

Berdasarkan hasil penelitian, terjadi reduksi intensitas cahaya jika cahaya melewati screen protector. Penambahan screen protector pada layar smartphone dapat memperlambat terjadinya degenerasi makula.

\section{DAFTAR PUSTAKA}

[1] Perdanam Jaka. 2012. 41 Juta Masyarakat Indonesia Miliki Smartphone, 95\%-nya Digunakan di Rumah. [Online]. Available:http://www.the-marketeers.com/archives/41-jutamasyarakat-indonesia-miliki-smartphone-95nya-digunakan-dirumah.html\#.U0111OJ3v4s. [Accessed:15-Apr-2014].

[2] 2015 Global Media Intelligence Report Executive Summary. https://www.emarketer.com/public_media/docs/GMI-2015ExecutiveSummary.pdf

[3] Rizal, Herr Fahrur. 2014. Technisia. http://id.technisia.com/orangindonesia-menggunakan-smartphone-189-menit-tiap-harinya-untuk apa-saja/

[4] Surya, Yohannes. Sunglasses kesehatan mata. Online. Tersedia di yohanessurya.com/download/penulis/Teknologi_35.pdf

[5] R.I. \& D.K. http://www.optikmelawai.com/kesehatan-mata/efeksinar-biru-bagi-kesehatan-mata.html

[6] Sutopo. Pengantar Fisika Kuantum. Malang, Jurusan Fisika Universitas Negeri Malang (2003), p. 35-54.

[7] Agus Purwanto. Fisika Kuantum. Yogyakarta: Gavamedia (2005), p. 13 . 